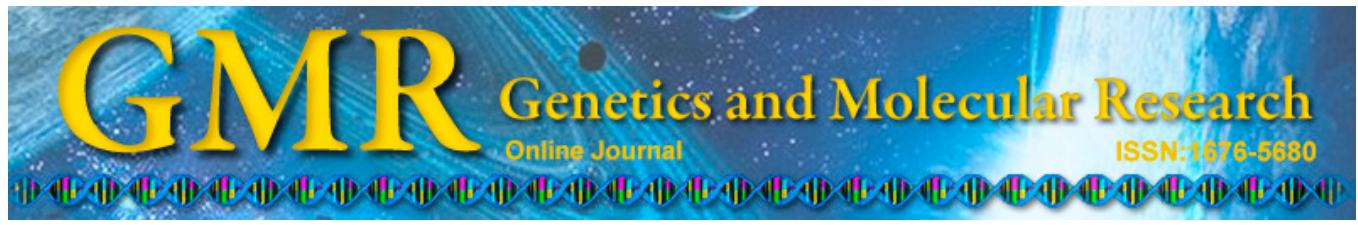

Brief Note

\title{
Low diversity of the major histocompatibility complex class II DRA gene in domestic goats (Capra hircus) in Southern China
}

\author{
L.P. Chen ${ }^{1 *}$, G.X. E ${ }^{1}$, Y.J. Zhao ${ }^{1}$, R.S. Na ${ }^{1}$, Z.Q. Zhao ${ }^{1}$, J.H. Zhang ${ }^{1}$, \\ Y.H. Ma ${ }^{2}$, Y.W. Sun ${ }^{1}$, T. Zhong ${ }^{3}$, H.P. Zhang ${ }^{3}$ and Y.F. Huang ${ }^{1 *}$ \\ ${ }^{1}$ College of Animal Science and Technology, \\ Chongqing Key Laboratory of Forage and Herbivores, \\ Chongqing Engineering Research Centre for Herbivores Resource Protection \\ and Utilization, Southwest University, Chongqing, China \\ ${ }^{2}$ Key Laboratory of Farm Animal Genetic Resources and Utilization of Ministry \\ of Agriculture, Institute of Animal Science, \\ Chinese Academy of Agricultural Sciences, Beijing, China \\ ${ }^{3}$ Farm Animal Genetic Resources Exploration and Innovation Key Laboratory \\ of Sichuan Province, Sichuan Agricultural University, Chengdu, Sichuan, China \\ *These authors contributed equally to this study. \\ Corresponding author: Y.F. Huang \\ E-mail: H67738337@swu.edu.cn
}

Genet. Mol. Res. 14 (2): 6925-6928 (2015)

Received January 6, 2015

Accepted May 25, 2015

Published June 18, 2015

DOI http://dx.doi.org/10.4238/2015.June.18.35

\begin{abstract}
DRA encodes the alpha chain of the DR heterodimer, is closely linked to DRB and is considered almost monomorphic in major histocompatibility complex region. In this study, we identified the exon 2 of DRA to evaluate the immunogenetic diversity of Chinese south indigenous goat. Two single nucleotide polymorphisms in an
\end{abstract}


untranslated region and one synonymous substitution in coding region were identified. These data suggest that high immunodiversity in native Chinese population.

Key words: Major histocompatibility complex; DRA; Domestic goat; Capra hircus

\section{INTRODUCTION}

The major histocompatibility complex (MHC) plays an important role in the adaptive immune response of vertebrates (Trowsdale, 1993). The DRA locus, which encodes the alpha chain of the DR heterodimer, is closely linked to DRB and is considered almost monomorphic (Ballingall et al., 2010). It exhibits low diversity in artiodactyl species (Sena et al., 2003; Sun et al., 2014), including its exon 2 (Sena et al., 2003; Zhou et al., 2007; Shafer et al., 2012). Therefore, investigating the diversity of the 2nd exon in the DRA of domestic goat breeds would help in understanding the specific evolutionary mechanism of the DRA gene, and realize the full breeding potential of Chinese goats.

\section{MATERIAL AND METHODS}

DNA samples were obtained from 247 individuals of 12 domestic goat breeds in southern China (Table 1). Screening for polymorphisms was performed by direct polymerase chain reaction (PCR) product sequencing in both directions. The primers and PCR protocol employed for the DRA exon 2 were the same as those used by Shafer et al. (2012). Linkage disequilibrium (LD) between loci within each population was analyzed by Genepop (Rousset, 2008). The heterozygosity $\left(H_{\mathrm{E}}\right.$ and $\left.H_{\mathrm{O}}\right)$ and polymorphism information content (PIC) were estimated using Microsatellite Toolkit (Park, 2001).

\section{RESULTS}

The total length of the aligned sequences was $303 \mathrm{bp}$, which included two singlenucleotide polymorphisms, the locations of which were based on AB008755: MI, C > T at $2373 \mathrm{bp}$ on the 2 nd intron, and one synonymous substitution (MII) in positions C $>$ T (p.Ala) at $2169 \mathrm{bp}$ on the 2 nd exon. In all of the populations studied, the MII site exhibited extremely low diversity $\left(H_{\mathrm{O}}=0.057, H_{\mathrm{E}}=0.0685\right.$, and $\left.\mathrm{PIC}=0.0631\right)$ in comparison to the MI site $\left(H_{\mathrm{E}}=\right.$ $0.471, H_{\mathrm{O}}=0.405$, and PIC $\left.=0.3525\right)$. We found unlinkage between MI and MII in all of the populations studied (Table 1).

\section{DISCUSSION}

Comparative analysis of the results obtained in our experiments revealed minimal diversity in exon 2 of the DRA gene. It seems to be highly conserved for residues that form the peptide-binding site region in the domestic goat, which is consistent with the fact that the gene is highly conserved in all of the mammalian species studied (Shafer et al., 2012; Sun et 
Diversity of DRA in goats

6927

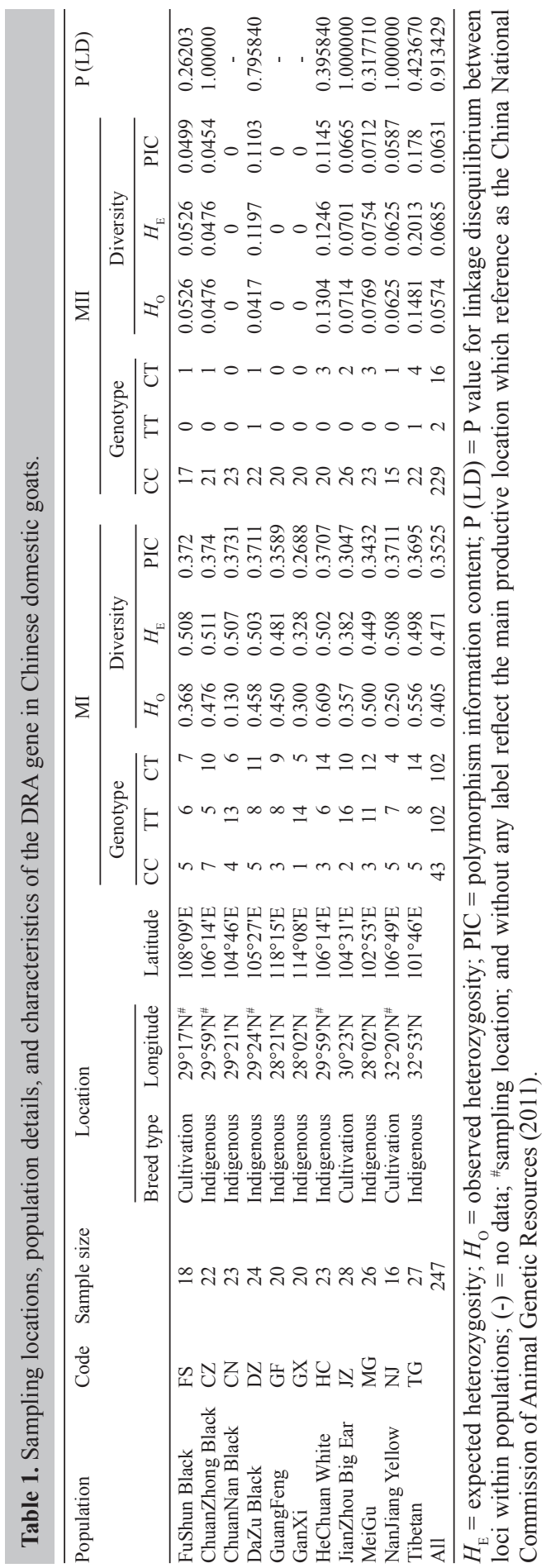


al., 2014). Directional selection appears to have conserved these specific functional regions (antigens that are specific to infectious xenobiotics) in the DRA gene of ruminant animals. In comparison to the monomorphic allele in the North American mountain goat (Oreamnos americanus) (Shafer et al., 2012), a weak but valuable variant of exon 2 in DRA indicates great potential to improve goat varieties and promote animal husbandry development in the Chinese domestic goat.

\section{Conflicts of interest}

The authors declare no conflict of interest.

\section{ACKNOWLEDGMENTS}

The authors alone are responsible for the content and writing of this article. Research supported by the Fundamental Research Funds for the Central Universities (\#SWU114023), the National Natural Science Foundation of China (\#31172195), and the 2013 Innovation Team Building Program in Chongqing Universities (\#KJTD201334).

\section{REFERENCES}

Ballingall KT, Rocchi MS, McKeever DJ and Wright F (2010). Trans-species polymorphism and selection in the MHC class II DRA genes of domestic sheep. PLoS One 5: e11402.

China National Commission of Animal Genetic Resources (2011). Animal genetic resources in China: sheep and goats. Chinese Agricultural Press, Beijing.

Park SDE (2001). Trypanotolerance in West African Cattle and the Population Genetic Effect of Selection. PhD Thesis, University of Dublin, Dublin.

Rousset F (2008). Genepop'007: a complete reimplementation of the Genepop software for Windows and Linux. Mol. Ecol. Resour. 8: 103-106.

Sena L, Schneider MPC, Brenig B, Honeycutt RL, et al. (2003). Polymorphisms in MHC-DRA and -DRB alleles of water buffalo (Bubalus bubalis) reveal different features from cattle DR alleles. Anim. Genet. 34: 1-10.

Shafer AB, Fan CW, Côté SD and Coltman DW (2012). (Lack of) genetic diversity in immune genes predates glacial isolation in the North American mountain goat (Oreamnos americanus). J. Hered. 103: 371-379.

Sun Y, Zheng H, Xi D, Zhang X, et al. (2014). Molecular characteristics of the MHC-DRA genes from yak (Bos grunniens) and Chinese yakow (Bos grunniens x Bos taurus). Int. J. Immunogenet. 41: 69-73.

Trowsdale J (1993). Genomic structure and function in the MHC. Trends Genet. 9: 117-122.

Zhou H, Hickford JG, Fang Q and Byun SO (2007). Identification of allelic variation at the bovine DRA locus by polymerase chain reaction-single strand conformational polymorphism. J. Dairy Sci. 90: 1943-1946. 